\title{
2,4-EPIBRASSIONOLIDE ACTIVATES PRIMING RESISTANCE AGAINST RHIZOPUS STOLONIFER INFECTION IN PEACH FRUIT
}

\author{
C.H. LI ${ }^{\mathrm{a}, \mathrm{b}}$, M.Y. Du ${ }^{\mathrm{b}, \mathrm{c}}$ and K.T. WANG ${ }^{\mathrm{a}, \mathrm{b}, \mathrm{*}}$ \\ ${ }^{\mathrm{a} C}$ College of Biology and Food Engineering, Chongqing Three Gorges University, Chongqing 404100. P.R. China \\ ${ }^{\mathrm{b}}$ Chinese-Hungarian Cooperative Research Centre for Food Science, Southwest University, Chongqing 400715. \\ P.R. China \\ ${ }^{\mathrm{c}}$ College of Food Science, Southwest University, Chongqing 400715. P.R. China
}

(Received: 29 December 2019; accepted: 3 February 2020)

This study was conducted to assess the effects of 2,4-epibrassionolide (EBR) on mold decay caused by Rhizopus stolonifer and its capability to activate biochemical defense reactions in postharvest peaches. The treatment of EBR at $5 \mu \mathrm{M}$ possessed the optimum effectiveness on inhibiting the Rhizopus rot in peach fruit among all treatments. The EBR treatment significantly up-regulated the expression levels of a set of defense-related enzymes and $P R$ genes that included PpCHI, PpGns1, PpPAL, PpNPR1, PpPR1 and PpPR4 as well as led to an enhancement for biosynthesis of phenolics and lignins in peaches during the incubation at $20^{\circ} \mathrm{C}$. Interestingly, the EBR-treated peaches exhibited more striking expressions of $P R$ genes and accumulation of antifungal compounds upon inoculation with the pathogen, indicating a priming defense could be activated by EBR. On the other hand, $5 \mu \mathrm{M}$ EBR exhibited direct toxicity on fungal proliferation of $R$. stolonifer in vitro. Thus, we concluded that $5 \mu \mathrm{M}$ EBR inhibited the Rhizopus rot in peach fruit probably by a direct inhibitory effect on pathogen growth and an indirect induction of a priming resistance. These findings provided a potential alternative for control of fungal infection in peaches during the postharvest storage.

Keywords: peach, 2,4-epibrassionolide (EBR), decay, induced resistance, Rhizopus stolonifer

Peaches (Prunus persica L.) are considered among the most cultivated horticultural crops throughout the world because of their attractive flavour and abundant phytonutrients (AUBERT \& Chalot, 2020). Nevertheless, harvested peach fruit ripen and deteriorate rapidly with the high susceptibility to fungal infections by a broad range of bacterial phytopathogens, resulting in severe economic losses. Rhizopus stolonifer (Ehrenb. ex Fr.) Vuill. is a representative necrotrophic fungal pathogen that brings about severe Rhizopus rot in peaches (RomANAzzI et al., 2016). Constrain on postharvest decay in agronomic fruits relies on the use of chemical fungicides mainly, but the public concerns over low-level chemical residuals in the environment and the development of pathogen resistance to some fungicides have grown dramatically in the last decade. Thus, there is an imperative need for natural substances to control postharvest diseases of fruits (RUSSELL, 2006).

Recently, brassinosteroid (BR) as a natural growth-promoting phytohormone has been catching the attention of researchers. Among the BRs, the most important compound of 2,4-epibrassionolide (EBR) has been well-documented to be an efficient inducer for both functions of regulating plant physiological processes and inducing the transcriptions of defense genes against pathogen attacks (FILEK et al., 2018). Furthermore, a few researches have displayed that EBR or BRs are potential candidates for "assisted phytoremediation" in

\footnotetext{
* To whom correspondence should be addressed.

Phone: +86 23 68250375; fax: +86 23 68251947; e-mail: wangkaituo83@gmail.com
} 
stress-responding systems and further up-regulated the resistances of model plant species to viral, bacterial, and fungal pathogens, such as barley (Ali et al., 2013), Arabidopsis thaliana (Albrecht et al., 2012), tobacco, and rice (NAKAshita et al., 2003). Nevertheless, limited data are available on the EBR induction on disease-resistance responses in agronomic fruits. Hence, the goal of the present research was to determine the most effective concentration of EBR to reduce decay caused by $R$. stolonifer on peaches and to analyse the molecular mechanisms involved.

\section{Materials and methods}

\subsection{Fruit and inoculum}

Typical commercially mature peaches (Prunus persica Batsch. cv. 'Baifeng') were picked manually from an organic vineyard located in Suining, Sichuan Province, southwestern China and transported to the laboratory within $2.5 \mathrm{~h}$. Mechanical-damage-free peaches without any visual infection with uniform size and colour were carefully chosen. The spore suspension of $R$. stolonifer was made by rinsing the spores from the edge of the one-week-old PDA culture of the pathogen with sterile water containing $0.05 \%$ Tween- 80 , and then the suspension concentration of $R$. stolonifer was set to $1.0 \times 10^{5}$ spores $\mathrm{ml}^{-1}$ using a haemocytometer counting chamber.

\subsection{Preliminary experiment}

In order to determine the optimal EBR concentration for inhibiting $R$. stolonifer infection, the selected peaches were superficially sterilised with ethanol $(75 \% \mathrm{v} / \mathrm{v})$, air-dried at ambient temperature, and then two uniform wounds (3-mm-deep and 3-mm-diameter) were punched around the equatorial zone. The wounded peaches were then randomly divided into four groups of 60 each. Afterwards, EBR solution at 0 (control), 1, 5, and $10 \mu \mathrm{M}$ were injected into the wounds in each group of peaches and subsequently inoculated with the spore suspension of $R$. stolonifer. All peaches were sealed in polyethylene bags (60- $\mu \mathrm{m}$ thickness) and incubated at $20 \pm 1{ }^{\circ} \mathrm{C}$ for $3 \mathrm{~d}$ with $80-90 \%$ R.H., and disease incidence was calculated at hours 24,48 , and 72 during the incubation period following our previous method (LI et al., 2020). Each treatment consisted of three replications, and the entire experiment was repeated in triplicate.

\subsection{Induction of disease resistance by EBR in peaches}

As our preliminary experiment showed, EBR at $5 \mu \mathrm{M}$ presented the lowest disease incidence and lesion diameter (Fig. 1). Therefore, $5 \mu \mathrm{M}$ EBR was employed to treat peaches in a subsequent experiment. The selected peaches were superficially sterilised and wounded as described in section 1.2, and then randomly divided into four groups of 90 each and treated as follows: (1) control peaches that were injected with distilled water alone; (2) EBR-treated peaches that were injected with EBR alone; (3) pathogen-inoculated peaches that were injected with $R$. stolonifer alone; and (4) EBR + inoculation, peaches were pre-injected with EBR following subsequent $R$. stolonifer inoculation. Afterwards, all peaches were incubated at $20 \pm 1{ }^{\circ} \mathrm{C}$ and $80-90 \%$ R.H. Healthy tissue samples were collected before the elicitations and at 12 -h intervals during $72 \mathrm{~h}$ of the incubation and then quick-frozen at $-80{ }^{\circ} \mathrm{C}$ for analysis of the induced resistance. Each treatment was employed based on a completely random scheme with three replications, and the experiment was carried out three times. 

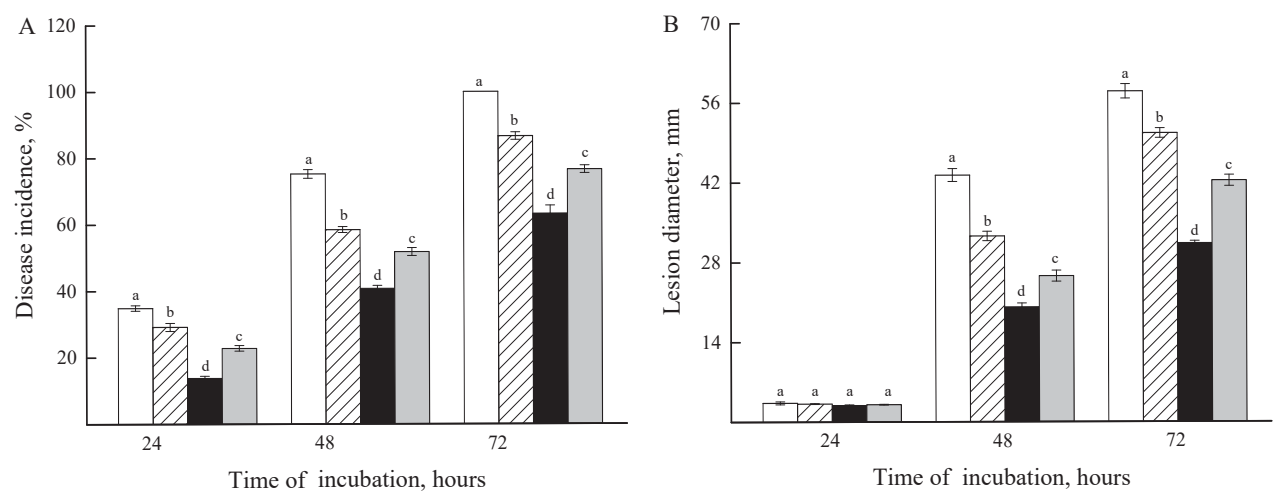

Fig. 1. Disease incidence (A) and lesion diameter (B) of peaches with $0,1,5$, and $10 \mu \mathrm{M}$ EBR treatment and $R$. stolonifer inoculation during $72 \mathrm{~h}$ of incubation. Data are expressed as the mean $\pm \mathrm{SE}$ of triplicate assays. Vertical bars represent the standard errors of the means. Different letters above the bars indicate statistically significant differences between treatments $(\mathrm{P}<0.05)$.

$\square:$ Inoculation; $囚: 1 \mu \mathrm{M}$ EBR+inoculation; $\square: 5 \mu \mathrm{M}$ EBR+inoculation; ㄴ: $10 \mu \mathrm{M}$ EBR+inoculation

\subsection{Total phenolic and lignin contents}

Total phenolics content was measured based on the procedure of Folin-Ciocalteu (SLINKARD \& Singleton, 1977), and the lignin content was gravimetrically quantified following the assay of Assis and co-workers (2001). Both parameters were expressed as milligrams per gram of FW (fresh weight).

\subsection{Gene expression of defense-related enzymes and PR genes}

The total RNA extraction from frozen tissue samples was carried out using RNAprep Pure Plant Plus Kit (DP441, Tiangen). Aliquots $(1 \mu \mathrm{g})$ of RNA were prepared to synthesize the first strand cDNA using a PrimeScript ${ }^{\mathrm{TM}} \mathrm{RT}$ reagent kit (RR037A, Takara). Quantitative realtime PCR (qRT-PCR) was conducted using TB Green ${ }^{\circledR}$ Fast qPCR Mix (RR430A, Takara) with the specific primers of resistance-related enzymes (PpCHI, PpGns1, PpPAL) and $P R$ genes ( $P p N P R 1, P p P R 1, P p P R 4)$, which are listed in Table S1. The qRT-PCR reactions were normalised by cycle threshold value according to the method of LIVAK and SCHMITTGEN (2001). The relative expression of defense-related enzymes and $P R$ genes were calibrated with the values for the day 0 fruit being set as 1 .

\subsection{Effect of EBR on spore germination of $\mathrm{R}$. stolonifer in vitro}

Spore germination and germ tube length of $R$. stolonifer were studied in potato dextrose broth (PDB) tubes following the method of WANG and co-workers (2015). One hundred microlitres of the spore suspension was transferred into the tubes with $5 \mathrm{ml} \mathrm{PDB}$ with or without $5 \mu \mathrm{M}$ EBR. All prepared tubes were incubated in a shaker $\left(100\right.$ r.p.m., $\left.26^{\circ} \mathrm{C}\right)$. After 12,24 , or 36 h, about 100 spores were evaluated for germination rate and germ tube length in three different microscopic fields. Spores were recognised as germinated when germ tube length was not lower than the largest diameter of the conidium. 


\subsection{Effect of EBR on mycelial growth of $\mathrm{R}$. stolonifer in vitro}

To tests the effect of EBR on mycelial growth of $R$. stolonifer, $20 \mathrm{ml}$ molten PDA at 50 60 ${ }^{\circ} \mathrm{C}$ were mixed with EBR to yield final concentrations of 0 or $5 \mu \mathrm{M}$ per Petri dish (diameter: $90 \mathrm{~mm}$ ). After the dishes solidified, a $5 \mathrm{~mm}$ R. stolonifer disc taken from the periphery of 5 -day-old culture was placed in the center of each PDA plate. All Petri plates were incubated at $26^{\circ} \mathrm{C}$ for 3 days. The effect of EBR on mycelial growth was calculated according to the formula:

Inhibitory rate on mycelial growth $(\%)=[(\mathrm{d} c-\mathrm{d} t) /(\mathrm{d} c-5 \mathrm{~mm})] \times 100 \%$,

where $\mathrm{d} c=$ average diameter of fungal colony in control and $\mathrm{d} t=$ average diameter of fungal colony in the treatment of EBR. Each treatment was replicated three times and the experiment was repeated three times.

\subsection{Statistical analysis}

The data presented were on the basis of the three independent experiments and shown as the means \pm standard errors (SE) of nine biological replicates. Statistical analysis was performed by one-way analysis of variance (ANOVA) followed by Duncan's multiple range test using the software SAS (ver. 8.2), and P-values $<0.05$ were considered to be significant.

\section{Results and discussion}

\subsection{Effects of EBR treatments on inhibiting Rhizopus rot in postharvest peaches}

Extensive research has manifested that BR metabolism serves as a rate-limiting regulator of BAK1 (a special interactor of Flagellin-Sensing 2) -mediated pathogen-associated molecular pattern (PAMP) responses (GrusZKA, 2013). As an active BR, 2,4-epibrassionolide (EBR) also exerted its biological role in eliciting resistance to pathogen or insect attacks in crops (KhrIPACH et al., 2000; Zhou et al., 2015). As can be seen in Fig. 1A, EBR treatment at 1 or $10 \mu \mathrm{M}$ caused a significant inhibitory effect on disease incidence over the time-course of the experiment compared with the controls. Specifically, treatment of peaches with $5 \mu \mathrm{M}$ EBR exhibited the most obvious effect on suppressing Rhizopus rot, with the disease incidence in the $5 \mu \mathrm{M}$ EBR-treated peaches being $26.93 \%$ or $17.40 \%$ lower than the 1 or $10 \mu \mathrm{M}$ EBRtreated samples at the end of the incubation, respectively. Simultaneously, the lesion diameter in peaches treated with $5 \mu \mathrm{M}$ EBR was significantly smaller than that seen in peaches with 1 or $10 \mu \mathrm{M}$ EBR-treated during the incubation (Fig. 1B). As shown in Figure 2, harvested peaches deteriorated more quickly once the fruit suffered from $R$. stolonifer infection. Remarkably, $5 \mu \mathrm{M}$ EBR treatment greatly delayed the degree of Rhizopus rot and the spread speed of hyphae on the epidermis of peach fruit during $72 \mathrm{~h}$ of incubation. Therefore, $5 \mu \mathrm{M}$ EBR was recognised as the optimum concentration in inhibiting the natural postharvest decay as well as the artificial infection caused by $R$. stolonifer in postharvest peaches, which indicated that the $5 \mu \mathrm{M}$ EBR was the appropriate measure to enhance disease resistance of peach fruit and to prevent fungal attack after harvest. 

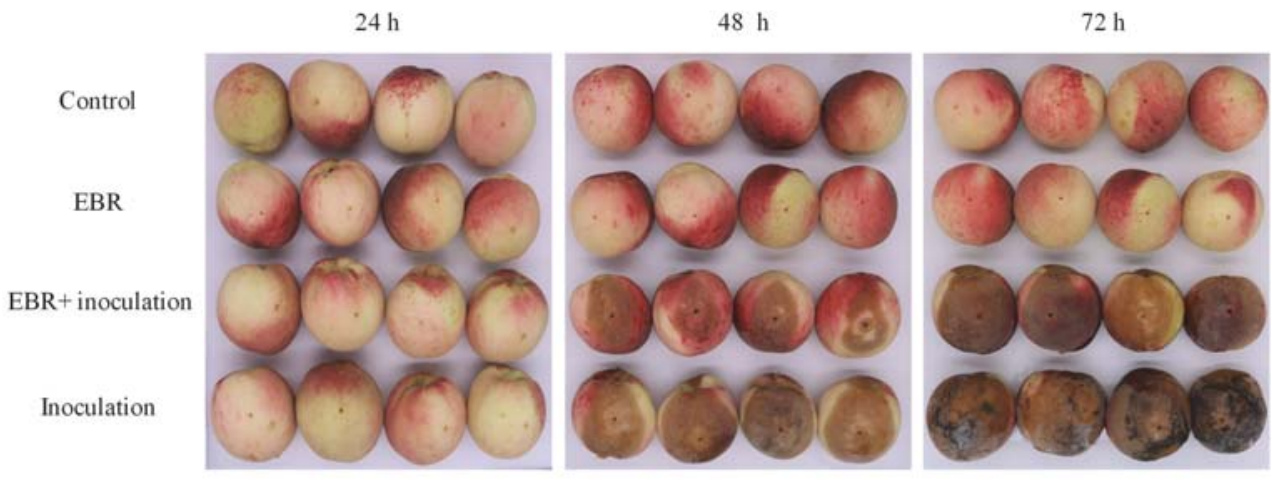

Fig. 2. Peach fruit with or without $5 \mu \mathrm{M}$ EBR treatment and $R$. stolonifer inoculation display significant appearance changes during $72 \mathrm{~h}$ of incubation. EBR and $R$. stolonifer inoculation experiments were conducted three times independently with similar results. Representative peaches were photographed and compared at $24 \mathrm{~h}$ intervals throughout the incubation period ( $24 \mathrm{~h}, 48 \mathrm{~h}$, and $72 \mathrm{~h}$ ).

\subsection{Effect of the EBR on the elicitation of resistance in peach fruit against $\mathrm{R}$. stolonifer infection}

Given that employing $5 \mu \mathrm{M}$ EBR conferred with the lowest Rhizopus rot in peaches, this concentration was chosen to analyse the effect of EBR on some parameters linked with induction of disease resistance.

Plants survive fungal pathogen attacks by exerting several layers of defensive reactions. They can rapidly perceive the presence of pathogens and elicitors responding by the induction of a highly coordinated cellular biochemical and structural defense system to restrict the development of pathogenic symptoms (MaOr \& SHIRASU, 2005). Among the $P R$ proteins, chitinase and $\beta-1,3$-glucanase, which possess the capability of hydrolyzing the polymers within fungal cell walls, are thought to be involved in the plant defense mechanisms against fungal infections (MAUCH et al., 1988). Phenylalanine ammonia lyase (PAL) is a critical enzyme in the phenylpropanoid pathway, which results in the biosynthesis of a variety of active metabolites, such as phytoalexins, phenols, and lignins (RyALs et al., 1996). In addition, accumulation of lignin and phenolics can consolidate a potent physical barrier against pathogen infection (MANDAL, 2010). In this study, the results revealed that the enhancement of disease resistance by EBR treatment was paralleled with the enhanced contents of total phenolics and lignins (Fig. 3) and the obvious increase on the gene expressions of a series of defense-related enzymes, such as phenylalanine ammonia-lyase ( $P p P A L)$, chitinase $(P p C H I)$ and $\beta$-1,3-glucanase ( $P p G n s 1$ ) (Fig. 4A-C). These results were consistent with the viewpoint of ZHU and co-workers (2008), who revealed that the increase in activities of chitinase, $\beta$-1,3glucanase and PAL could contribute to the resistance against pathogen infection. Moreover, PpNPRI is highly homologous with the Arabidopsis thaliana NPR1 gene (Fig. S1), showing similar defensive behavior in activating the expression of pathogen-related genes for combating pathogens (KINKEMA et al., 2000). The peaches with $5 \mu \mathrm{M}$ EBR treatment alone have less significant capabilities to induce immediate and strong transcript level changes in the three $P R$ genes including $P p N P R 1, P p P R 1$, and PpPR4 (Fig. 4D-F), on the contrary, the subsequent $R$. stolonifer inoculation triggered a remarkable defensive response and enhanced the transcript values of the $P R$ genes, which implied that the induced resistance mediated by 
EBR should not be employed as a direct response. Because the EBR alone failed to induce phenotypic defence traits, we inferred that this pathogen-dependent resistance in EBR-treated peaches can be attributed to a priming mechanism for expressing magnified molecular defensive responses upon pathogen invasions. These findings support our previous researches on antagonistic bacterium and BABA ( $\beta$-aminobutyric acid) -induced resistance in strawberry and grapefruit, demonstrating that the elicitor applied at relative low dose/concentration could lead to a priming mechanism to confer necessary resistance against various postharvest diseases (WANG et al., 2016; 2019).
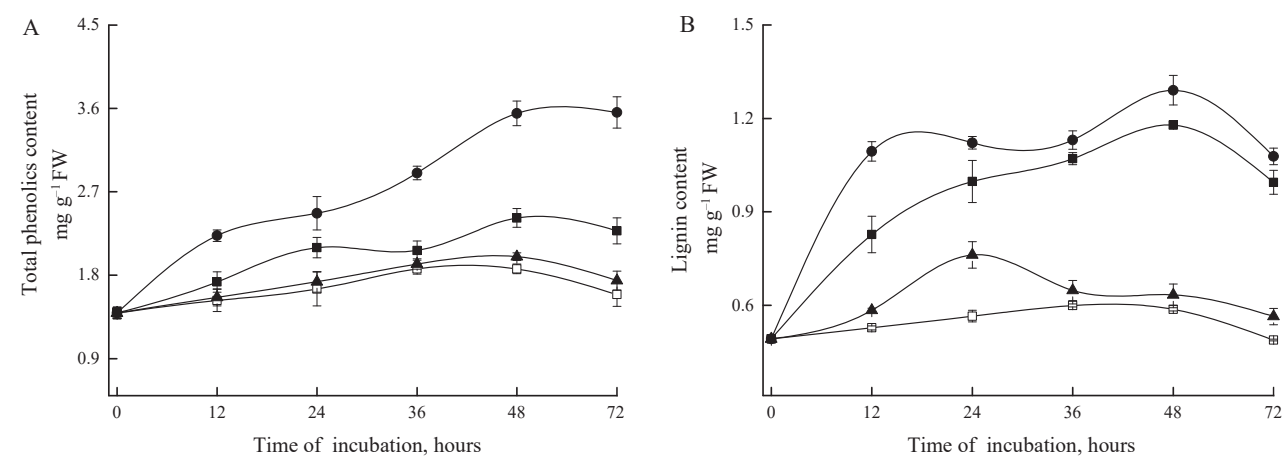

Fig. 3. Changes in the contents of total phenolics (A) and lignin (B) in peach fruit with or without EBR treatment and $R$. stolonifer inoculation during $72 \mathrm{~h}$ of incubation. Data are expressed as the mean $\pm \mathrm{SE}$ of triplicate assays. Vertical bars represent the standard errors of the means.

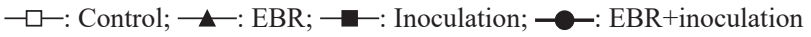

It is noteworthy that PpNPR1 is a key mediator protein in plant signal transduction pathway, causing the activation of SAR (Systemic Acquired Resistance) (KINKEMA et al., 2000). Alternatively, PpPR1, a marker gene of the SA (salicylic acid) -independent signalling pathway, was evidently up-regulated in EBR-primed peaches infected with $R$. stolonifer (Fig. 4E). Thus, SAR presumably participates in the EBR-elicited priming state for inciting sustainable increases in defensive response upon pathogen invasions.

\subsection{In vitro efficacy of $5 \mu M E B R$ on the growth of $\mathrm{R}$. stolonifer}

Addition of $5 \mu \mathrm{M}$ EBR to the minimal medium strongly restricted spore germination and germ tube elongation of $R$. stolonifer in PDB tubes, both of which were obviously retarded when compared with the controls at each time point (Table S2). Meanwhile, EBR treatment also markedly restrained the mycelial growth of $R$. stolonifer in vitro during $72 \mathrm{~h}$ incubation, and the inhibitory rate presented a growing trend within the incubation time $\left(r=0.96^{* *}\right)$ (Table $\mathrm{S} 2$ ). Hence, our results confirmed that $5 \mu \mathrm{M}$ EBR might have direct lethal effects on $R$. stolonifer, ultimately resulting in an inhibition of Rhizopus rot on peaches. This direct effectiveness of EBR in controlling fungal infection of table grape was also described by LiU and co-workers (2016) through epidermal spraying. 

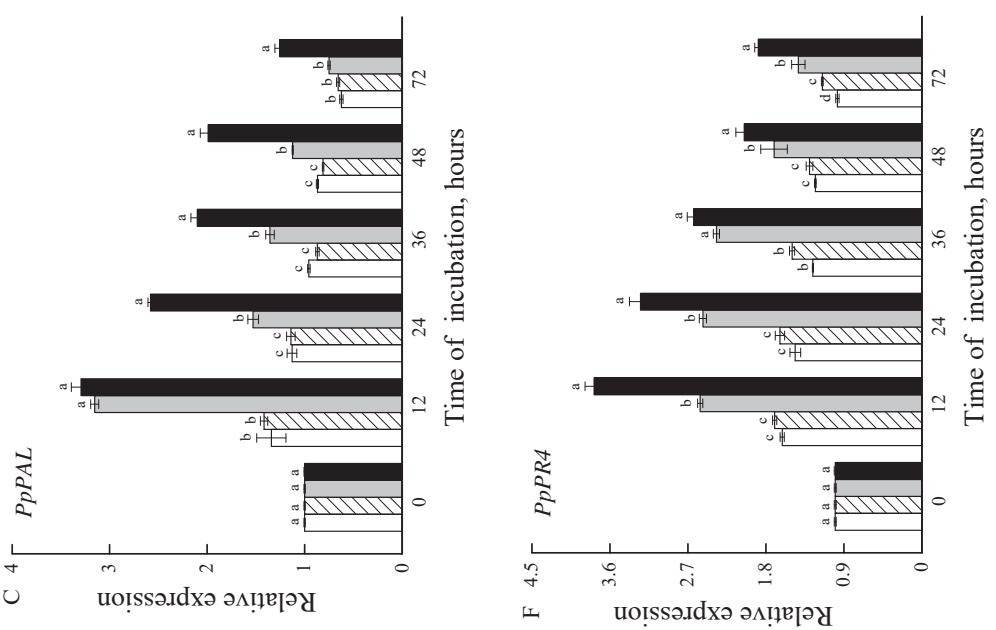

뚱

되

要

후를

吾

节

동

竞:

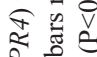

₹. त्

इ

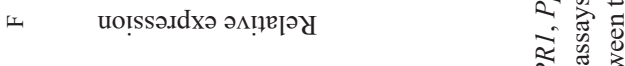
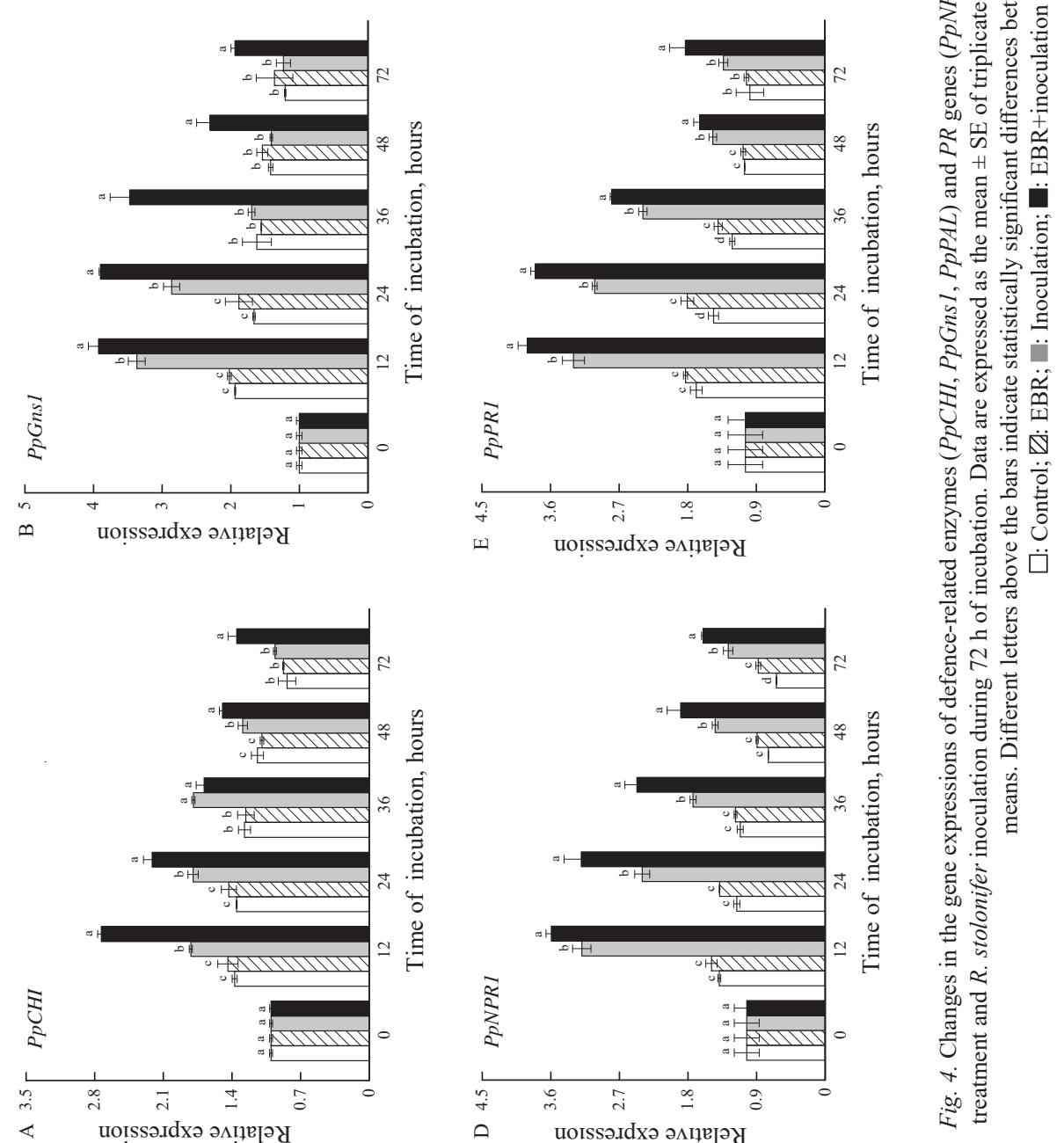


\section{Conclusions}

In addition to its direct inhibitory effects on $R$. stolonifer growth, treatment with $5 \mu \mathrm{M}$ EBR activated the significant disease resistance against Rhizopus rot in postharvest peaches during the incubation. The EBR-induced resistance in the present study was a typical priming defense, which primed peaches for the enhanced expression of $P R s$ and biosynthesis of lignin and phenolics upon challenge with $R$. stolonifer. Thus, the EBR treatment restricted the development of Rhizopus rot in peaches through dual different modes including direct fungal toxicity and indirect induced priming defense. Since priming defense represents a "costeffective" feature in evolutional disease strategy in plants by minimizing plant growth cost and fruit quality loss when compared to the direct defense (CONRATH et al., 2015), we suggest $5 \mu \mathrm{M}$ EBR treatment for the potential control of Rhizopus rot in postharvest peach industry during distribution and storage.

This study was supported by the National Natural Science Foundation of China (No. 31671913 and 31672209) and the Funding Project for Fifth Excellent Talents in the Universities of Chongqing City (201731).

\section{References}

Albrecht, C., Boutrot, F., Segonzac, C., Schwessinger, B., Gimenez-Ibanez, S., ... \& Zipfel, C. (2012): Brassinosteroids inhibit pathogen-associated molecular pattern-triggered immune signaling independent of the receptor kinase BAK1. Proc. Natl. Acad. Sci. US A, 109, 303-308.

Ali, S.S., Kumar, G.B., Khan, M. \& Doohan, F.M. (2013): Brassinosteroid enhances resistance to fusarium diseases of barley. Phytopathology, 103, 1260-1267.

Assis, J.S., Maldonado, R., Muñoz, T., Escribano, M.I. \& Merodio, C. (2001): Effect of high carbon dioxide concentration on PAL activity and phenolic contents in ripening cherimoya fruit. Postharvest Biol. Tec., 23, 33-39.

Aubert, C. \& CHAlot, G. (2020): Physicochemical characteristics, vitamin C, and polyphenolic composition of four European commercial blood-flesh peach cultivars (Prunus persica L. Batsch). J. Food Compos. Anal., 86, $103337-103347$

Conrath, U., Beckers, G.J.M., Langenbach, C.J.G. \& Jaskiewicz, M.R. (2015): Priming for enhanced defense. Annu. Rev. Phytopathol., 53, 97-119.

Filek, M., Sieprawska, A., OklestKowa, J., Rudolphi-Skórska, E., Biesaga-Kościelniak, J., ... \& Janeczko, A. (2018): 2,4-Epibrassinolide as a modifier of antioxidant activities and membrane properties of wheat cells in zearalenone stress conditions. J. Plant Growth Regul., 37, 1085-1098.

GruszKa, D. (2013): The brassinosteroid signaling pathway - New key players and interconnections with other signaling networks crucial for plant development and stress tolerance. Int. J. Mol. Sci., 14, 8740-8774.

KhripaCH, V., ZhabinskiI, V. \& GroOt, A.D. (2000): Twenty years of brassinosteroids: steroidal plant hormones warrant better crops for the XXI century. Ann. Bot., 86, 441-447.

KInkema, M., FAn, W.H. \& Dong, X.N. (2000): Nuclear localization of NPR1 is required for activation of PR gene expression. Plant Cell, 12, 2339-2350.

Li, C., Wang, J., Ji, N., Lei, C., Zhou, D., ... \& WANG, K. (2020): PpHOS1, a RING E3 ubiquitin ligase, interacts with PpWRKY22 in the BABA-induced priming defence of peach fruit against Rhizopus stolonifer. Postharvest Biol. Tec., 159, 111029-111037.

Liu, Q., Xi, Z., GaO, J., Meng, Y., Lin, S. \& Zhang, Z. (2016): Effects of exogenous 24-epibrassinolide to control grey mould and maintain postharvest quality of table grapes. Int. J. Food Sci. Tech., 51, 1236-1243.

LivaK, K.J. \& SCHMitTGEN, T.D. (2001): Analysis of relative gene expression data using real-time quantitative PCR and the $2^{-\triangle \Delta C T}$ method. Methods, 25, 402-408.

Mandal, S. (2010): Induction of phenolics, lignin and key defence enzymes in eggplant (Solanum melongena L.) roots in response to elicitors. Afr. J. Biotechnol., 9, 8038-8047. 
MaOr, R. \& ShIRASU, K. (2005): The arms race continues: battle strategies between plants and fungal pathogens. Curr. Opin. Microbiol., 8, 399-404.

Mauch, F., Mauch-Mani, B. \& Boller, T. (1988): Antifungal hydrolase in pea tissue: II. Inhibition of fungal growth by combination of chitinase and $\beta-1,3$-glucanase. Plant Physiol., 88, 936-942.

Nakashita, H., Yasuda, M., NitTa, T., Asami, T., Fujioka, S... \& Yoshida, S. (2003): Brassinosteroid functions in a broad range of disease resistance in tobacco and rice. Plant J., 33, 887-898.

Romanazzi, G., Sanzani, S.M., Bi, Y., Tian, S.P., Martínez, P.G. \& Alkan, N. (2016): Induced resistance to control postharvest decay of fruit and vegetables. Postharvest Biol. Tec., 122, 82-94.

Russell, P.E. (2006): The development of commercial disease control. Plant Pathol., 55, 585-594.

Ryals, J.A., Neuenschwander, U.H., Willits, M.G., Molina, A., Steiner, H.Y. \& Hunt, M.D. (1996): Systemic acquired resistance. Plant Cell, 124, 1809-1819.

SlinKARD, K. \& Singleton, V.L. (1977): Total phenol analysis: Automation and comparison with manual methods. Am. J. Enol. Viticult., 28, 49-55.

WANG, K., CAO, S., Di, Y., LiaO, Y. \& ZHENG, Y. (2015): Effect of ethanol treatment on disease resistance against anthracnose rot in postharvest loquat fruit. Sci. Hortic., 188, 115-121.

WANG, K., LiAO, Y., XIONG, Q., KaI, J., CAO, S. \& ZHENG, Y. (2016): Induction of direct or priming resistance against Botrytis cinerea in strawberries by $\beta$-aminobutyric acid and their effects on sucrose metabolism. J. Agr. Food Chem., 64, 5855-5865.

WANG, K., Wu, D., Guo, D. \& Du, M. (2019): $\beta$-aminobutyric acid induces disease resistance against Botrytis cinerea in grape berries by a cellular priming mechanism. Acta Alimentaria, 48, 177-186.

Zhou, Y., XIA, X., YU, G., WANG, J., WU, J., ... \& YU, J. (2015): Brassinosteroids play a critical role in the regulation of pesticide metabolism in crop plants. Sci. Rep.-UK, 5, 9018-9024.

ZhU, X., CAO, J., WANG, Q. \& JIANG, W. (2008): Postharvest infiltration of BTH reduces infection of mango fruits (Mangifera indica L. cv. Tainong) by Colletotrichum gloeosporioides and enhances resistance inducing compounds. J. Phytopathol., 156, 68-74. 